\title{
Carbon Nanotubes as Adsorbent of Solid-Phase Extraction and Matrix for Laser Desorption/Ionization Mass Spectrometry
}

\author{
Chensong Pan, Songyun Xu, Hanfa Zou, Zhong Guo, Yu Zhang, \\ and Baochuan Guo* \\ National Chromatographic R and A Center, Dalian Institute of Chemical Physics, Graduate School \\ of the Chinese Academy of Sciences, Dalian, China
}

\begin{abstract}
A method with carbon nanotubes functioning both as the adsorbent of solid-phase extraction (SPE) and the matrix for matrix assisted laser desorption/ionization mass spectrometry (MALDI-MS) to analyze small molecules in solution has been developed. In this method, $10 \mu \mathrm{L}$ suspensions of carbon nanotubes in 50\% ( $\mathrm{vol} / \mathrm{vol}$ ) methanol were added to the sample solution to extract analytes onto surface of carbon nanotubes because of their dramatic hydrophobicity. Carbon nanotubes in solution are deposited onto the bottom of tube with centrifugation. After removing the supernatant fluid, carbon nanotubes are suspended again with dispersant and pipetted directly onto the sample target of the MALDI-MS to perform a mass spectrometric analysis. It was demonstrated by analysis of a variety of small molecules that the resolution of peaks and the efficiency of desorption/ionization on the carbon nanotubes are better than those on the activated carbon. It is found that with the addition of glycerol and sucrose to the dispersant, the intensity, the ratio of signal to noise $(\mathrm{S} / \mathrm{N})$, and the resolution of peaks for analytes by mass spectrometry increased greatly. Compared with the previously reported method by depositing sample solution onto thin layer of carbon nanotubes, it is observed that the detection limit for analytes can be enhanced about 10 to 100 times due to solid-phase extraction of analytes in solution by carbon nanotubes. An acceptable result of simultaneously quantitative analysis of three analytes in solution has been achieved. The application in determining drugs spiked into urine has also been realized. (J Am Soc Mass Spectrom 2005, 16, 263-270) (C) 2004 American Society for Mass Spectrometry
\end{abstract}

$\mathrm{M}$ atrix assisted laser desorption/ionization time of flight mass spectrometry (MALDI-TOFMS) $[1,2]$ has a wide range of application in various fields [3-8] because it is tolerant to buffers, salts, and other additives in the sample. However, the quality of MALDI mass spectrum still strongly depends on sample preparation, and its detection capability is always limited by the presence of contaminants. To overcome these limitations, considerable efforts have been made to develop several different approaches. The integration of small reversed-phase columns $[9,10]$ for sample preparation prior to MALDI-TOF-MS has been demonstrated to be efficient in concentration of analytes and removing salt contaminant. Other methods were reported for the treatment of surface of the sample support including washing on sample support [11],

Published online December 21, 2004

Address reprint requests to Dr. H. Zou, National Chromatographic R and A Center, Dalian Institute of Chemical Physics, Chinese Academy of Sciences, 161 Zhongshan Road, Dalian 116011, China. E-mail: hanfazou@dicp.ac.cn and zouhfa@mail.dlptt.ln.cn

* Also at the Department of Chemistry, Cleveland State University, Ohio 44115 , USA. coating with a self-assembled monomolecular layer of $\mathrm{C}_{18}[12,13]$, prestructured with a thin layer of hydrophobic Teflon, etc. [14, 15].

Carbon nanotubes have attracted great attention because of their unique properties in structure, mechanics, electrics, and electromechanics [16-20] since they were initially discovered by Iijima [21,22]. Recently, the ability of carbon nanotubes for adsorption of analytes is demonstrated by some works [23-28], and a carbon nanotube-packed column for solid-phase extraction (SPE) of bisphenol A, 4-n-nonylphenol and 4-tertoctylphenol in the environmental sample has been developed. It is believed that carbon nanotubes might be a kind of unique adsorbent in SPE because of their dramatically hydrophobic surface.

On the other hand, carbon nanotubes have been used as the matrix in MALDI-TOF-MS for analysis of small molecules in our group [29]. In that work, a sample droplet was pipetted onto the matrix layer of carbon nanotubes that is pre-deposited on the sample target of MALDI-TOF-MS, in which carbon nanotubes functioned both as the energy receptacle for laser radiation and the energy transporter for the desorption/ioniza- 
tion of analytes; it was demonstrated that carbon nanotubes could be a good matrix for analysis of a number of small molecules without the matrix ion interference.

In this work, a method with carbon nanotubes functioning both as the adsorbent for solid-phase extraction (SPE) of analytes in solution and as the matrix for MALDI-TOF-MS for the analysis of adsorbed analytes has been developed. It is observed that the detection limit for low-mass analytes could be enhanced about 10 to 100 times through SPE procedure, and simultaneously quantitative analysis of mixture of small molecules in solution was achieved. Furthermore, it is found that with the addition of glycerol and sucrose into the dispersant, the intensity, the ratio of signal to noise $(\mathrm{S} / \mathrm{N})$, and the resolution of peaks for analytes by mass spectrometry increased significantly. It is believed that this method greatly simplified the sample preparation with integration of concentration, desalting and removing contaminants prior to MALDI-TOF-MS.

\section{Experimental}

\section{Chemicals and Materials}

Multiwalled carbon nanotubes were kindly provided by Professor Y. L. Guo (Shanghai Institute of Organic Chemistry, CAS, Shanghai, China) and activated carbon was obtained from Liaoning Chemical Factory (Liaoning, China). $\mathrm{N}_{\alpha}$-Benzoyl-L-Arginine (B-Arg), $\mathrm{N}_{\alpha}$-Z-L-Arginine (Z-Arg), $\mathrm{N}_{\alpha}$-Benzoyl-L-arginine ethyl ester (BAEE) hydrochloride, and $\mathrm{N}_{\alpha}$-benzoyl-DL-arginine-4-nitroanilide (BAPNA) hydrochloride were purchased from Fluka (Buchs, Switzerland). Drugs of propranolol, cinchonine, and quinine were purchased from Shanghai Chemical Factory (Shanghai, China). Peptides of Leu-Tyr and LeuMet were obtained from Serva (Feinbiochemica, Heidelberg, Germany). Other reagents were of analytical grade with the exception of methanol and acetonitrile, which were of HPLC grade. The water used in all experiments was obtained from a Milli-Q water purification system (Millipore, Milford, MA).

\section{Procedure of SPE for Carbon Nanotubes and Activated Carbon}

Ten mg carbon nanotubes were first rinsed with acetonitrile and water twice, respectively, then suspended in 1.0 $\mathrm{mL} \mathrm{50 \%} \mathrm{(vol/vol)} \mathrm{methanol} \mathrm{with} \mathrm{the} \mathrm{sonication} \mathrm{for} 3 \mathrm{~min}$. Ten $\mu \mathrm{L}$ suspensions of the carbon nanotubes was pipetted into the $100 \mu \mathrm{L}$ or $1000 \mu \mathrm{L}$ of analytes solution in centrifuge tube immediately. With sonication less than $5 \mathrm{~s}$, carbon nanotubes were homogeneously spread in the solution and the analytes were extracted from the liquid phase to the surface of carbon nanotubes in $10 \mathrm{~min}$. After centrifugation at 10,000 rpm for $10 \mathrm{~min}$, carbon nanotubes adsorbed with analytes were deposited on the bottom of the centrifuge tube. Then the supernatant was removed, and $5 \mu \mathrm{L}$ dispersant solution of $50 \%$ methanol ( $\mathrm{vol} / \mathrm{vol}$ ) without or with the addition of glycerol and sucrose was added into centrifuge tube to suspend the carbon nanotubes again. Finally, about $1 \mu \mathrm{L}$ suspension of the carbon nanotubes was pipetted onto the sample target of the MALDI-TOF-MS. The sample target was left at room temperature for 10 to $15 \mathrm{~min}$ for evaporation of the solvent and for further analysis by MALDI-TOF-MS. Activated carbon was first ground into powder, followed by the procedure of SPE in exactly the same way described above for carbon nanotubes.

\section{Preparation of Analyte Solutions}

Propranolol, cinchonine, and quinine were all dissolved in water at the concentration of $100 \mathrm{ppm}$ as storage solution and other different concentrations were prepared by dilution step by step. The storage solution of a mixture of three drugs (3DrugMix) was composed of propranolol, cinchonine, and quinine with the concentration of $10 \mathrm{ppm}$ each. The storage solution of B-Arg, BAEE, Z-Arg, and BAPNA was also prepared by dissolving them in water at the concentration of $1000 \mathrm{ppm}$, respectively, and other different concentrations were also prepared by dilution. All storage solutions were refrigerated at around $4{ }^{\circ} \mathrm{C}$ for usage.

\section{Pretreatment of Urine Sample}

Nine hundred $\mu \mathrm{L}$ newly collected urine sample was first spiked with $100 \mu \mathrm{L}$ drug solutions at different concentration, then the $\mathrm{pH}$ value of urine sample was adjusted to 8 or 9 by a concentrated ammonia solution. Next, the urine sample was put in the freezer at a temperature of around $-20^{\circ} \mathrm{C}$ for about $30 \mathrm{~min}$ to be frozen completely, then transferred to cold storage around $4{ }^{\circ} \mathrm{C}$ for another $30 \mathrm{~min}$ to thaw. Finally, the urine sample was centrifuged at 10,000 rpm for $10 \mathrm{~min}$ to remove the deposition. The procedure for SPE of drugs in urine sample is almost the same as the procedure described above except that after carbon nanotubes were deposited from urine solution under centrifugation, it was necessary to rinse the carbon nanotubes at least three times with $100 \mu \mathrm{L}$ water to remove most of the non-adsorbed compounds on the surface of carbon nanotubes, such as salts and hydrophilic metabolites. Subsequently, carbon nanotubes were mixed with dispersant solution and transferred onto the sample target with drugs extracted from urine for mass spectrometric analysis.

\section{Mass Spectrometric Analysis}

MALDI-TOF-MS was performed on the Bruker Autoflex $^{\mathrm{TM}}$ (Bruker Co., Bremen, Germany). The instrument was equipped with a nitrogen laser $(\lambda=337 \mathrm{~nm})$ and its available accelerating potential is in the range of $+20 /-20 \mathrm{kV}$. The MALDI uses a ground-steel sample target, on which the carbon nanotubes with analyte is deposited and dried. The analytical range of laser energy was adjusted to slightly above the threshold to obtain 

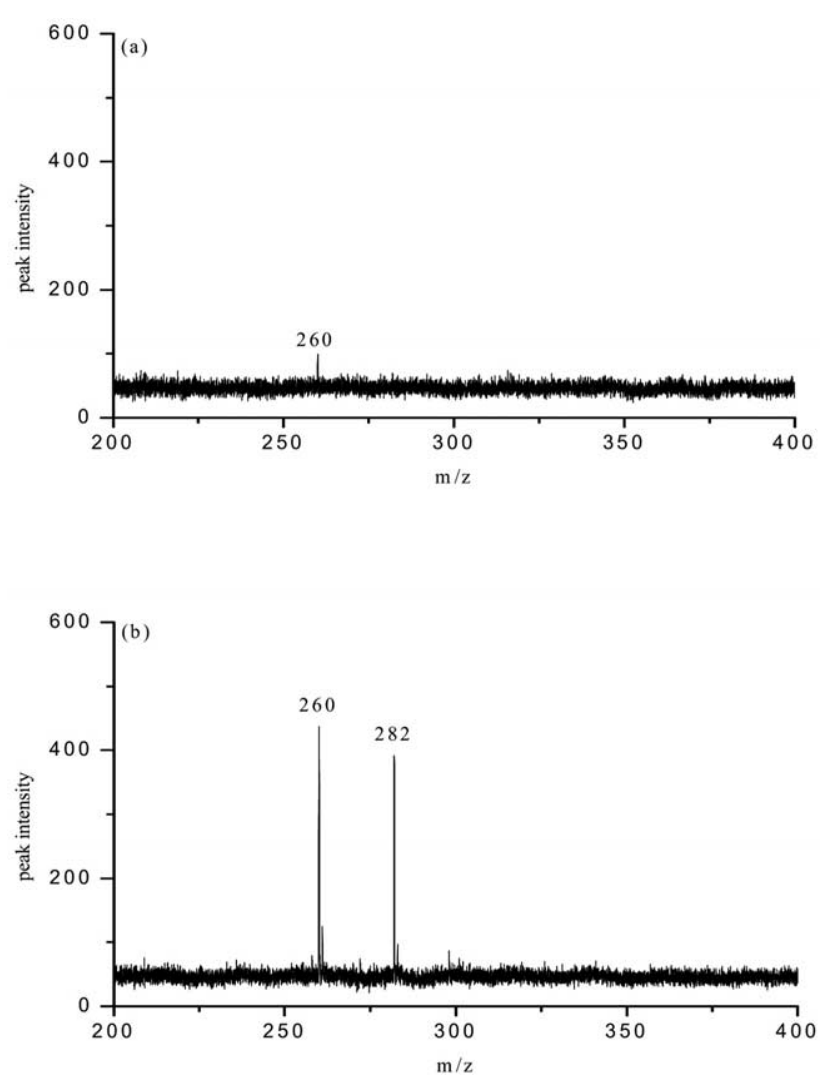

Figure 1. Mass spectra of propranolol extracted from $100 \mu \mathrm{L}$ solutions at $100 \mathrm{ppm}$ with (a) activated carbon and (b) carbon nanotubes as adsorbent for SPE and matrix for MALDI, respectively. The mass spectra were obtained with the laser power adjusted to slightly above the threshold energy for propranolol with the matrix of activated carbon. Peaks at $m / z 260$ and 282 are assigned to be the $\mathrm{H}^{+}$and $\mathrm{Na}^{+}$adduct ion of propranolol.

good resolution and signal-to-noise ratios. Unless otherwise noted, all mass spectra shown were obtained in the positive-ion reflection mode under pressure less than $1 \times 10^{-4} \mathrm{~Pa}$ with delayed time of $40 \mathrm{~ns}$; each spectrum was typically added by 30 laser shots. External mass calibration was obtained by using two points that bracketed the mass range of interest.

\section{Results and Discussion}

\section{Methodology}

For a comparison of carbon nanotubes with activated carbon, the activated carbon was also applied to function both as the adsorbent for SPE and the matrix for MALDI-TOF-MS ${ }^{\circ}$ analysis. ${ }^{\circ}$ Figure $^{\circ} 1^{\circ}$ shows $^{\circ}$ the ${ }^{\circ}$ mass spectra of propranolol extracted from $100 \mu \mathrm{L}$ solutions at $100 \mathrm{ppm}$ with (Figure a) activated carbon and (Figure b) carbon nanotubes as adsorbent for SPE and matrix for MALDI, respectively. The mass spectra in

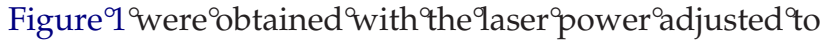
slightly above the threshold energy for propranolol with matrix of activated carbon. Note that the dominant peaks for propranolol $\left(260,[\mathrm{M}+\mathrm{H}]^{+} ; 282,[\mathrm{M}+\mathrm{Na}]^{+}\right)$ are $^{\circ}$ detected ${ }^{\circ}{ }^{\circ}{ }^{\circ}$ Figure $^{\circ} 1 \mathrm{~b},{ }^{\circ}$ while ${ }^{\circ}$ only $^{\circ} \mathrm{a}^{\circ}$ minor $^{\circ}$ peak ${ }^{\circ}$ at $\mathrm{m} / \mathrm{z} 260^{\circ}$ is $^{\circ}$ detected $^{\circ}$ in $^{\circ}$ Figure $^{\circ} 1$ a $^{\circ}{ }^{\circ}$ Both $^{\circ}$ spectra ${ }^{\circ}$ were obtained with the solution of $50 \%$ ( $\mathrm{vol} / \mathrm{vol}$ ) methanol as dispersant. The comparative experiments with SPE adsorbent and matrix of carbon nanotubes and activated carbon were also conducted with a variety of small molecules, and the intensity, the ratio of signal to noise $(\mathrm{S} / \mathrm{N})$, and the resolution of peaks for B-Arg, BAEE, propranolol, quinine, Leu-Tyr, and Leu-Met are listed in ${ }^{\circ}$ Table $^{\circ} 1 .^{\circ}{ }^{\circ}$ From $^{\circ}$ Table $^{\circ} 1{ }^{\circ}{ }^{\text {it }}{ }^{\circ}{ }^{\circ} s^{\circ}$ observed ${ }^{\circ}$ that ${ }^{\circ}$ all ${ }^{\circ}$ parameters for mass spectrum on carbon nanotubes are better than those on activated carbon. The improvement of resolution of peaks for analytes might result from the fact that the size of carbon nanotubes is much smaller than that of activated carbon. The enhancement of the intensity and $\mathrm{S} / \mathrm{N}$ of peaks for analytes demonstrated that the efficiency for desorption/ionization of analytes on the surface of carbon nanotubes is better than that on the surface of activated carbon, which might be explained by their difference in structure: carbon nanotubes are surrounded with streams of conjugated electrons in the side-wall and could function both as the energy receptacle for UV laser radiation and the energy transporter for the desorption/ionization of analytes, while activated carbon could only adsorb the UV radiation but could not transfer energy to analytes fluently. Other comparative works were also conducted on carbon nanotubes and activated carbon by analysis of small $^{\circ}$ molecules ${ }^{\circ}$ listed $^{\circ}$ in $^{\circ}$ Table $^{\circ} 1^{\circ}$ with $^{\circ}$ the ${ }^{\circ}$ thin ${ }^{\circ}$ layer $\operatorname{method}^{\circ}[29]$, in $^{\circ}$ which $^{\circ} 1^{\circ} \mu \mathrm{L}^{\circ}$ analyte ${ }^{\circ}$ solution ${ }^{\circ}$ was ${ }^{\circ}$ pipetted directly onto the thin-layer formed by depositing 1 $\mu \mathrm{L}$ suspension of carbon nanotubes and activated carbon in $50 \%$ ( $\mathrm{vol} / \mathrm{vol})$ methanol, respectively. It was found that few compounds could be detected on the matrix of activated carbon, while all compounds could be well detected on the matrix of carbon nanotubes. Alhough the activated carbon is a good adsorbent for SPE because of its hydrophobic property, the relatively poor efficiency for desorption/ionization of analytes on its surface limited its application as matrix for MALDI.

Initially, $50 \%$ (vol/vol) methanol was selected as the dispersant for suspending the carbon nanotubes before and after SPE of analytes. It was found that the signal for analytes was short-lived and carbon nanotubes could occasionally fly off from the sample target under the vacuum after solvent was evaporated. To overcome these limitations, small amounts of glycerol and sucrose were added into the dispersant at the same time to extend time periods of ion signal and minimize the possible contamination of ion source, which is inspired by the method of surface-assisted laser desorption/ ionization $^{\circ}(\mathrm{SALDI})^{\circ}\left[30^{\circ}-34\right] .{ }^{\circ} \mathrm{But}^{\circ}{ }^{\circ} \mathrm{t}^{\circ}$ was $^{\circ}{ }^{\circ}$ ound ${ }^{\circ}$ that ${ }^{\circ}$ the signal for analytes was still short live because most glycerol was quickly evaporated under vacuum in the ion source and during sample preparation before MALDI-TOF-MS analysis. However, it is surprising to see that there is a steep rise in the intensity and $\mathrm{S} / \mathrm{N}$ of peaks for analytes by mass spectrometry with the addition of both the glycerol and sucrose in the dispers- 
Table 1. Comparative list of the intensity, the ratio of signal to noise (S/N) and the resolution of peaks for analytes by MALDI-TOFMS with activated carbon (AC) and carbon nanotubes (CNTs) as adsorbent for SPE and matrix for MALDI. All analytes were extracted from $100 \mu \mathrm{L}$ solution with B-Arg, BAEE at $1000 \mathrm{ppm}$ and propranolol, quinine, Leu-Tyr, and Leu-Met at $100 \mathrm{ppm}$. All parameters of instrument for each analyte are kept constant and the laser energy is adjusted to slightly above the threshold of analytes in the case of with matrix of activated carbon.

\begin{tabular}{|c|c|c|c|c|c|c|c|}
\hline & \multirow[b]{2}{*}{$m / z$} & \multicolumn{2}{|c|}{ Intensity $\left(\times 10^{2}\right)$} & \multicolumn{2}{|c|}{$\mathrm{S} / \mathrm{N}\left(\times 10^{1}\right)$} & \multicolumn{2}{|c|}{ Resolution $\left(\times 10^{3}\right)$} \\
\hline & & $A C$ & CNTs & $A C$ & CNTs & $A C$ & CNTs \\
\hline \multirow[t]{3}{*}{ B-Arg } & {$[\mathrm{M}+\mathrm{H}]^{+}, 279$} & 1.5 & 5.9 & 1.2 & 4.5 & 0.90 & 2.4 \\
\hline & {$[\mathrm{M}+\mathrm{Na}]^{+}, 301$} & $\mathrm{~N}$ & 2.2 & $N$ & 1.7 & $N$ & 2.1 \\
\hline & {$[\mathrm{M}+\mathrm{K}]^{+}, 317$} & $\mathrm{~N}$ & 1.5 & $\mathrm{~N}$ & 1.1 & $\mathrm{~N}$ & 1.6 \\
\hline \multirow[t]{3}{*}{ BAEE } & {$[\mathrm{M}+\mathrm{H}]^{+}, 307$} & 1.9 & 4.3 & 1.6 & 3.6 & 1.6 & 1.7 \\
\hline & {$[\mathrm{M}+\mathrm{Na}]^{+}, 329$} & 1.1 & 2.5 & 0.93 & 2.2 & 1.2 & 2.3 \\
\hline & {$[\mathrm{M}+\mathrm{K}]^{+}, 345$} & 1.1 & 1.1 & 0.92 & 0.92 & 1.3 & 2.2 \\
\hline \multirow[t]{3}{*}{ propranolol } & {$[\mathrm{M}+\mathrm{H}]^{+}, 260$} & 0.99 & 4.4 & 0.67 & 3.2 & 0.96 & 1.9 \\
\hline & {$[\mathrm{M}+\mathrm{Na}]^{+}, 282$} & $\mathrm{~N}$ & 3.9 & $\mathrm{~N}$ & 2.9 & $\mathrm{~N}$ & 1.8 \\
\hline & {$[\mathrm{M}+\mathrm{K}]^{+}, 298$} & $\mathrm{~N}$ & $\mathrm{~N}$ & $N$ & $\mathrm{~N}$ & $\mathrm{~N}$ & $\mathrm{~N}$ \\
\hline \multirow[t]{3}{*}{ quinine } & {$[\mathrm{M}+\mathrm{H}]^{+}, 325$} & 1.0 & 3.8 & 0.77 & 2.9 & 1.2 & 2.2 \\
\hline & {$[\mathrm{M}+\mathrm{Na}]^{+}, 347$} & $\mathrm{~N}$ & 1.8 & $\mathrm{~N}$ & 1.3 & $\mathrm{~N}$ & 2.5 \\
\hline & {$[\mathrm{M}+\mathrm{K}]^{+}, 363$} & $\mathrm{~N}$ & $\mathrm{~N}$ & $\mathrm{~N}$ & $\mathrm{~N}$ & $\mathrm{~N}$ & $\mathrm{~N}$ \\
\hline \multirow[t]{3}{*}{ Leu-Tyr } & {$[\mathrm{M}+\mathrm{H}]^{+}, 295$} & $\mathrm{~N}$ & $\mathrm{~N}$ & $\mathrm{~N}$ & $\mathrm{~N}$ & $\mathrm{~N}$ & $\mathrm{~N}$ \\
\hline & {$[\mathrm{M}+\mathrm{Na}]^{+}, 317$} & 1.1 & 6.1 & 0.87 & 3.8 & 0.53 & 2.8 \\
\hline & {$[\mathrm{M}+\mathrm{K}]^{+}, 333$} & 0.91 & 1.6 & 0.72 & 1.0 & 0.65 & 2.4 \\
\hline \multirow[t]{3}{*}{ Leu-Met } & {$[\mathrm{M}+\mathrm{H}]^{+}, 263$} & $\mathrm{~N}$ & $\mathrm{~N}$ & $\mathrm{~N}$ & $\mathrm{~N}$ & $N$ & $\mathrm{~N}$ \\
\hline & {$[\mathrm{M}+\mathrm{Na}]^{+}, 285$} & 0.96 & 3.4 & 0.81 & 1.9 & 0.72 & 2.2 \\
\hline & {$[\mathrm{M}+\mathrm{K}]^{+}, 301$} & 1.1 & 2.0 & 0.85 & 1.2 & 0.67 & 2.1 \\
\hline
\end{tabular}

$\mathrm{AC}=$ with activated carbon as adsorbent for SPE and matrix for MALDI; CNTs = with carbon nanotubes as adsorbent for SPE and matrix for MALDI; $\mathrm{N}=$ not detected.

ant ${ }^{\circ}$ solution..$^{\circ}$ Figure ${ }^{\circ} 2^{\circ}$ shows ${ }^{\circ}$ the $e^{\circ}$ mass $^{\circ}$ spectra ${ }^{\circ}$ of ${ }^{\circ}$ propranolol extracted from $100 \mu \mathrm{L}$ solution at $100 \mathrm{ppm}$ by carbon nanotubes with suspension by $5 \mu \mathrm{L}$ dispersant

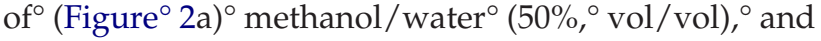
(Figure $\left.^{\circ} 2 \mathrm{~b}\right)^{\circ}$ methanol $/$ water $^{\circ}\left(50 \%,{ }^{\circ} \mathrm{vol} / \mathrm{vol}\right)^{\circ}$ with $^{\circ}$ the addition of $5 \%$ (vol/vol) glycerol and $1 \%(\mathrm{wt} / \mathrm{wt})$ sucrose, respectively. The dominant peak of $\mathrm{H}^{+}$adducted ion for propranolol $\left(260,\left[\mathrm{M}+\mathrm{H}^{+}\right)\right.$is well detected with the $\mathrm{Na}^{+} / \mathrm{K}^{+}$adduct ion for sucrose (365,

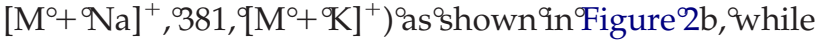
minor peaks for propranolol $\left(260,[\mathrm{M}+\mathrm{H}]^{+} ; 282,[\mathrm{M}+\right.$ $\mathrm{Na}^{+}{ }^{\circ}{ }^{\circ}$ are $^{\circ}$ detected $^{\circ}$ in $^{\circ}$ Figure $^{\circ} 2$ a $^{\circ}$ Table $^{\circ} 2^{\circ}$ shows $^{\circ}$ the comparative list of the intensity, $\mathrm{S} / \mathrm{N}$ and resolution of peaks for B-Arg, BAEE, propranolol, quinine, Leu-Tyr, and Leu-Met, which were extracted by carbon nanotubes from $100 \mu \mathrm{L}$ solution by using dispersant without and with the addition of $5 \%(\mathrm{vol} / \mathrm{vol})$ glycerol and $1 \%$ $(w t / w t)$ sucrose, respectively. It is clearly indicated that the intensity, the $\mathrm{S} / \mathrm{N}$, and the resolution of peaks of $\mathrm{H}^{+}$ adduct ion for analytes increased significantly with the addition of glycerol and sucrose, while peaks of $\mathrm{Na}^{+} / \mathrm{K}^{+}$adduct ion for analytes were not changed markedly or not even detected. It is believed that the residue of glycerol and sucrose play a very important role in the process of desorption/ionization for analytes on the surface of carbon nanotubes. We can only speculate that the residue of glycerol acted as a cationizing agent to enhance the intensity and the $\mathrm{S} / \mathrm{N}$ of peaks for analytes by providing more $\mathrm{H}^{+} / \mathrm{Na}^{+} / \mathrm{K}^{+}$and assisting the desorption/ionization of analytes at a lower ${ }^{\circ}$ temperature $[30,31],{ }^{\circ}$ while ${ }^{\circ}$ the ${ }^{\circ}$ sucrose $^{\circ}$ served $^{\circ}$ as collisionally cool desorbing molecules to improve the resolution of peaks and the proportion of $\mathrm{H}^{+}$adduct ion ${ }^{\circ}$ for ${ }^{\circ}$ analytes ${ }^{\circ}[35,36]$.

By taking this advantage, $50 \%$ (vol/vol) methanol with the addition of $5 \%$ (vol/vol) glycerol and 1\% $(\mathrm{W} / \mathrm{W})$ sucrose was adopted as the dispersant in all followed ${ }^{\circ}$ experiments. ${ }^{\circ}$ Figure $^{\circ} 3^{\circ}$ shows $^{\circ}$ the ${ }^{\circ}$ mass $^{\circ}$ spectrum for analytes extracted by carbon nanotubes from $100 \mu \mathrm{L}$ 3DrugMix solution composed of propranolol $\left(260,[\mathrm{M}+\mathrm{H}]^{+}\right)$, cinchonine $\left(295,[\mathrm{M}+\mathrm{H}]^{+}\right)$, and quinine $\left(325,[\mathrm{M}+\mathrm{H}]^{+}\right)$at a concentration of $10 \mathrm{ppm}$ for $^{\circ}$ each. ${ }^{\circ}$ From $^{\circ}$ the ${ }^{\circ}$ mass $^{\circ}$ spectra $^{\circ}$ shown ${ }^{\circ}$ in ${ }^{\circ}$ Figure $^{\circ} 3$, it can clearly be seen that all analytes were extracted from the solution and well detected on carbon nanotubes, which shows the large capacity of carbon nanotubes for adsorption of analytes in solution. Because of the introduction of glycerol and sucrose in the dispersant, the background peaks in the mass spectrum are $\mathrm{Na}^{+}, \mathrm{K}^{+}$, and the $\mathrm{Na}^{+} / \mathrm{K}^{+}$adduct ions with glycerol (at $m / z 115$ and 131) and sucrose (at $\mathrm{m} / \mathrm{z} 365$ and 381) and sometimes the fragments of sucrose at $\mathrm{m} / \mathrm{z} 185,203$, and the $\mathrm{Na}^{+}$adduct ion with the diglycerol at $m / z 189$ would appear as minor peaks as increase the laser energy.

In comparison with our previously reported thinlayer ${ }^{\circ}$ method ${ }^{\circ}[29]^{\circ}{ }^{\circ}{ }^{\circ}$ which $^{\circ} 1^{\circ} \mu \mathrm{L}^{\circ}$ analyte ${ }^{\circ}$ solution ${ }^{\circ}$ was pipetted directly onto the thin-layer formed by depositing $1 \mu \mathrm{L}$ suspension of carbon nanotubes, the greatest advantage of the present method is that the analytes are extracted from a large volume solution and concentrated onto the surface of carbon nanotubes. Incidentally, it not only increased the intensity and $\mathrm{S} / \mathrm{N}$ of the 

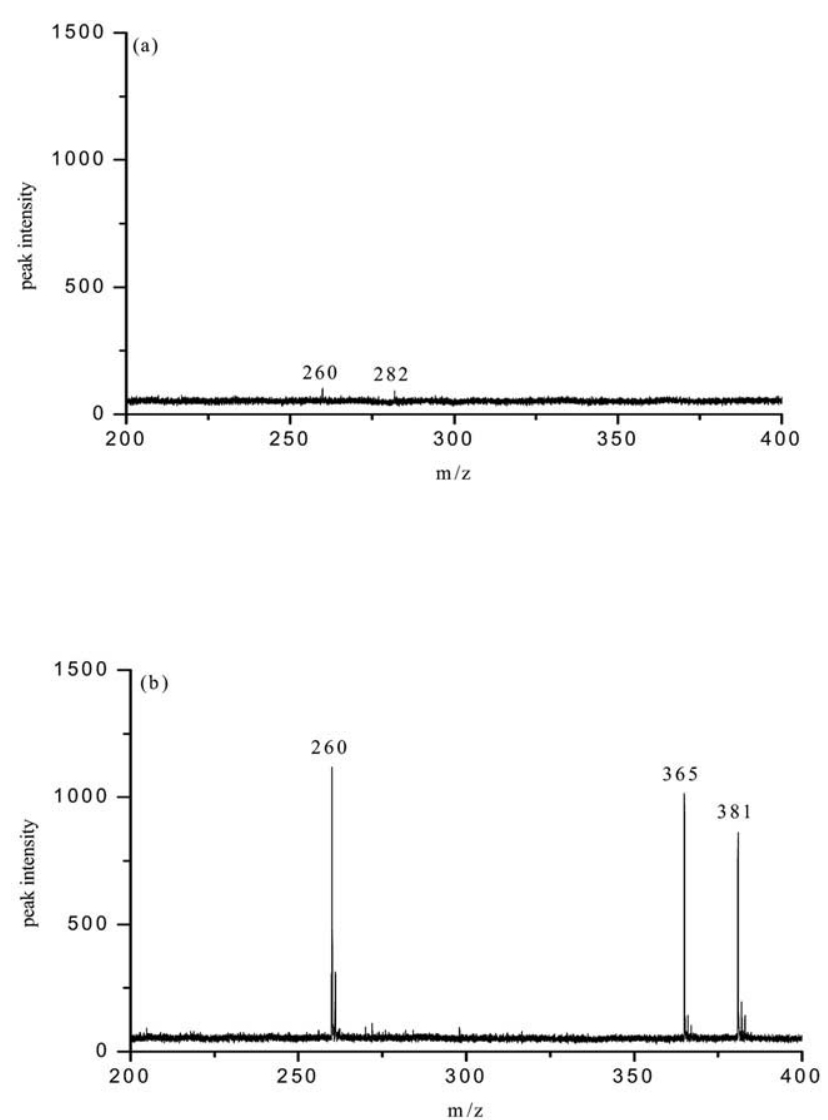

Figure 2. Mass spectra of propranolol adsorbed on the surface of carbon nanotubes extracted from $100 \mu \mathrm{L}$ solution at $100 \mathrm{ppm}$ with the $5 \mu \mathrm{L}$ dispersant of (a) methanol/water ( $50 \%$, vol/vol), and (b) methanol/water $(50 \%, \mathrm{vol} / \mathrm{vol})$ with the addition of $1 \%(\mathrm{wt} / \mathrm{wt})$ sucrose and $5 \%$ (vol/vol) glycerol. The mass were obtained with the laser power adjusted to slightly above the threshold energy for propranolol without the addition of glycerol and sucrose into the dispersant. Peaks at $m / z 260$ and 282 are assigned to be the $\mathrm{H}^{+}$and $\mathrm{Na}^{+}$adduct ion for propranolol, and peaks at $m / z 365$ and 381 are assigned to be the $\mathrm{Na}^{+}$and $\mathrm{K}^{+}$adduct ion for sucrose in (b).

spectrum but also lowered the limit of detection of analytes. ${ }^{\circ}$ Figure ${ }^{\circ}{ }^{\circ}$ shows $^{\circ}$ the ${ }^{\circ}$ mass $^{\circ}$ spectrum ${ }^{\circ}$ of ${ }^{\circ}$ quinine marked with asterisk at the concentration of $500 \mathrm{ppb}, 50$ $\mathrm{ppb}^{\circ}$ and $^{\circ} 5^{\circ} \mathrm{ppb}^{\circ}{ }^{\circ}$ from $^{\circ}$ top $^{\circ}$ to $^{\circ}$ bottom $^{\circ}$ by $^{\circ}$ (Figure ${ }^{\circ} 4 \mathrm{a}$ ) thin-layer ${ }^{\circ}$ method, $^{\circ}\left(\text { Figure }^{\circ} 4 \mathrm{~b}\right)^{\circ} \mathrm{SPE}^{\circ}$ method $^{\circ}$ extracted from ${ }^{\circ} 100^{\circ} \mu \mathrm{L}^{\circ}$ solution, ${ }^{\circ}$ and ${ }^{\circ}$ (Figure $\left.{ }^{\circ} 4 \mathrm{c}\right)^{\circ}$ extracted $^{\circ}$ from $1000 \mu \mathrm{L}$ solution. By keeping quinine at the same concentration, the intensity and $\mathrm{S} / \mathrm{N}$ of the spectra shown ${ }^{\circ}$ in $^{\circ}$ Figure $^{\circ} 3^{\circ}$ increased $^{\circ}$ from ${ }^{\circ}$ left $^{\circ}{ }^{\circ} o^{\circ}$ right, ${ }^{\circ}$ apparently. The limit of detection for quinine is about $500 \mathrm{ppb}$ in the thin-layer method, $50 \mathrm{ppb}$ in the SPE extraction from $100 \mu \mathrm{L}$ solution, and $5 \mathrm{ppb}$ from $1000 \mu \mathrm{L}$ solution with the $\mathrm{S} / \mathrm{N} \approx 3$. Obviously, the quinine in solution was enriched from 10 to 100 times by carbon nanotubes and hence lowered the limit of detection for quinine through this SPE process.

\section{Quantitative Analysis}

SPE method also shows a great potential in quantitative analysis for low-mass compounds. Z-Arg was selected as the internal standard (IS) for three analytes in the mixture (3ArgMix) comprised of B-Arg, BAEE and BAPNA with the varied concentration of each component attributable to their similarity in structure. Carbon nanotubes with analytes extracted from solution were pipetted onto the target of MALDI and dried at room temperature, then $0.5 \mu \mathrm{L}$ solution of Z-Arg, which was prepared by diluting the stock solution of Z-Arg with methanol at $154 \mathrm{ppm}$, was pipetted onto the surface of carbon nanotubes as the IS for quantitative analysis. The mass spectrum of analytes extracted from $100 \mu \mathrm{L}$ 3ArgMix solutions with the concentration of $27.8 \mathrm{ppm}$ for B-Arg, $30.6 \mathrm{ppm}$ for BAEE, and $39.8 \mathrm{ppm}$ for BAPNA, followed by depositing $0.5 \mu \mathrm{L}$ solution of Z-Arg ${ }^{\circ}{ }^{\circ} 154^{\circ}$ ppm $^{\circ}$ is ${ }^{\circ}$ shown ${ }^{\circ}$ in the Figure 5 . Peaks ${ }^{\circ}{ }^{\circ} \mathrm{m} / \mathrm{z}$ $279,307,399$, and 309 could be assigned to the $\mathrm{H}^{+}$ adduct ions of B-Arg, BAEE, BAPNA, and Z-Arg, respectively. The dominant peak at $m / z 309$ for Z-Arg was selected as the IS for quantitative analysis. The obtained quantitative calibration curves between the relative intensity ( $\mathrm{I}_{\text {analytes }} / \mathrm{I}_{\mathrm{Z} \text {-Arg }}$ ) of analyte peaks to Z-Arg peak and concentrations of analytes are shown in Figure $^{\circ} 6 .^{\circ}$ Every $^{\circ} \operatorname{dot}^{\circ}$ in $^{\circ}$ Figure $^{\circ} 6^{\circ}$ is ${ }^{\circ}$ the ${ }^{\circ}$ average ${ }^{\circ}$ of ${ }^{\circ}$ five spectra and each spectrum is accumulated from 30 laser shots at 10 different laser spots, i.e., a total of 300 laser shots for each. The values of $\mathrm{R}^{2}$ for B-Arg, BAEE, and BAPNA are $0.9879,0.9864$ and 0.9829 , respectively. Because of the saturation of adsorption capacity for analytes on the surface of carbon nanotubes, the relative intensity $\left(\mathrm{I}_{\text {analytes }} / \mathrm{I}_{\mathrm{Z} \text {-Arg }}\right)$ of all analytes seems not to rise with the increase in concentration when it is larger than $15 \mathrm{ppm}$. In any case, the linear range of calibration curves for analytes in 3ArgMix solution is from about 1 to $10 \mathrm{ppm}$, and the reproducibility between sample spots is acceptable for MALDI-TOF-MS analysis with values of RSD around 20\%.

\section{Urine Sample Analysis}

The application of this SPE method in determining drugs spiked into urine sample was also investigated. After SPE extraction of drugs in urine solution by carbon nanotubes, they were rinsed with water several times to remove salts and hydrophilic metabolites. Figure ${ }^{\circ} 7^{\circ}$ shows $^{\circ}$ mass $^{\circ}$ spectra $^{\circ}$ for ${ }^{\circ}$ analytes ${ }^{\circ}$ adsorbed on carbon nanotubes by SPE extraction from (Figure $\left.^{\circ} 7 \mathrm{a}\right)^{\circ} 100^{\circ} \mu \mathrm{L}^{\circ}$ blank $^{\circ}$ urine $^{\circ}$ sample, $^{\circ}\left(\right.$ Figure $^{\circ} 7 \mathrm{~b}$ ) $100 \mu \mathrm{L}$ urine sample spiked with quinine (325, [M + $\left.\mathrm{H}]^{+}\right)^{\circ}$ at $^{\circ}$ the $^{\circ}$ concentration $^{\circ}$ of $^{\circ}{ }^{\circ}{ }^{\circ} \mathrm{ppm}^{\circ}$, and $^{\circ}$ ( Figure $^{\circ} 7 \mathrm{c}$ ) spiked with 3DrugMix solution containing propranolol $\left(260,[\mathrm{M}+\mathrm{H}]^{+}\right)$, cinchonine $\left(295,[\mathrm{M}+\mathrm{H}]^{+}\right)$, and quinine $\left(325,[\mathrm{M}+\mathrm{H}]^{+}\right)$with concentration of each component at $3 \mathrm{ppm}$. Although most of the salts and hydrophilic metabolites are removed by cold storage and centrifugation before extraction as well as by rinsing the carbon nanotubes after extraction with water, some compounds in urine are still adsorbed on the surface of carbon nanotubes and detected in the MALDI-TOF ${ }^{\circ} \mathrm{MS}^{\circ}$ as $^{\circ}$ shown $^{\circ}$ in ${ }^{\circ}$ Figure $^{\circ} 7 .{ }^{\circ}$ The ${ }^{\circ}$ presence 
Table 2. Comparative list of the intensity, the ratio of signal to noise $(\mathrm{S} / \mathrm{N})$ and the resolution of peaks for analytes adsorbed on the surface of carbon nanotubes by MALDI-TOF-MS without and with the addition of glycerol and sucrose into the dispersant. All analytes were extracted from $100 \mu \mathrm{L}$ solution with B-Arg, BAEE at $1000 \mathrm{ppm}$ and propranolol, quinine, Leu-Tyr, and Leu-Met at $100 \mathrm{ppm}$. All parameters of instrument for each analyte are kept constant and the laser energy is adjusted to slightly above the threshold of analytes in the case of without the addition of glycerol and sucrose into the dispersant.

\begin{tabular}{|c|c|c|c|c|c|c|c|}
\hline & \multirow[b]{2}{*}{$m / z$} & \multicolumn{2}{|c|}{ Intensity $\left(\times 10^{2}\right)$} & \multicolumn{2}{|c|}{$\mathrm{S} / \mathrm{N}\left(\times 10^{1}\right)$} & \multicolumn{2}{|c|}{ Resolution $\left(\times 10^{3}\right)$} \\
\hline & & (A) & (B) & (A) & (B) & (A) & (B) \\
\hline \multirow[t]{3}{*}{ B-Arg } & {$[\mathrm{M}+\mathrm{H}]^{+}, 279$} & 3.5 & 24 & 2.1 & 20 & 1.1 & 1.9 \\
\hline & {$[\mathrm{M}+\mathrm{Na}]^{+}, 301$} & 1.9 & 23 & 1.1 & 1.8 & 1.2 & 1.9 \\
\hline & {$[\mathrm{M}+\mathrm{K}]^{+}, 317$} & 1.3 & 2.9 & 0.74 & 2.3 & 1.1 & 1.9 \\
\hline \multirow[t]{3}{*}{ BAEE } & {$[\mathrm{M}+\mathrm{H}]^{+}, 307$} & 1.6 & 17 & 1.2 & 15 & 1.1 & 1.8 \\
\hline & {$[\mathrm{M}+\mathrm{Na}]^{+}, 329$} & 0.98 & 1.1 & 0.73 & 1.0 & 0.87 & 1.7 \\
\hline & {$[\mathrm{M}+\mathrm{K}]^{+}, 345$} & 0.88 & 1.1 & 0.65 & 1.0 & 1.3 & 1.3 \\
\hline \multirow[t]{3}{*}{ propranolol } & {$[\mathrm{M}+\mathrm{H}]^{+}, 260$} & 1.0 & 11 & 0.84 & 8.3 & 0.81 & 2.1 \\
\hline & {$[\mathrm{M}+\mathrm{Na}]^{+}, 282$} & 0.93 & $\mathrm{~N}$ & 0.75 & $\mathrm{~N}$ & 0.99 & $\mathrm{~N}$ \\
\hline & {$[\mathrm{M}+\mathrm{K}]^{+}, 298$} & $\mathrm{~N}$ & $\mathrm{~N}$ & $\mathrm{~N}$ & $\mathrm{~N}$ & $\mathrm{~N}$ & $\mathrm{~N}$ \\
\hline \multirow[t]{3}{*}{ quinine } & {$[\mathrm{M}+\mathrm{H}]^{+}, 325$} & 1.7 & 4.5 & 1.4 & 3.6 & 1.7 & 2.9 \\
\hline & {$[\mathrm{M}+\mathrm{Na}]^{+}, 347$} & 0.82 & $\mathrm{~N}$ & 0.65 & $\mathrm{~N}$ & 0.75 & $\mathrm{~N}$ \\
\hline & {$[\mathrm{M}+\mathrm{K}]^{+}, 363$} & $\mathrm{~N}$ & $\mathrm{~N}$ & $\mathrm{~N}$ & $\mathrm{~N}$ & $\mathrm{~N}$ & $\mathrm{~N}$ \\
\hline \multirow[t]{3}{*}{ Leu-Tyr } & {$[\mathrm{M}+\mathrm{H}]^{+}, 295$} & $\mathrm{~N}$ & 5.5 & $\mathrm{~N}$ & 3.6 & $\mathrm{~N}$ & 1.9 \\
\hline & {$[\mathrm{M}+\mathrm{Na}]^{+}, 317$} & 2.0 & 1.4 & 1.8 & 0.95 & 1.6 & 1.1 \\
\hline & {$[\mathrm{M}+\mathrm{K}]^{+}, 333$} & 1.1 & 2.0 & 1.0 & 1.3 & 1.6 & 1.5 \\
\hline \multirow[t]{3}{*}{ Leu-Met } & {$[\mathrm{M}+\mathrm{H}]^{+}, 263$} & $\mathrm{~N}$ & 2.9 & $\mathrm{~N}$ & 2.2 & $\mathrm{~N}$ & 2.4 \\
\hline & {$[\mathrm{M}+\mathrm{Na}]^{+}, 285$} & 0.90 & 0.86 & 0.67 & 0.66 & 1.0 & 1.0 \\
\hline & {$[\mathrm{M}+\mathrm{K}]^{+}, 301$} & $\mathrm{~N}$ & 1.8 & $\mathrm{~N}$ & 1.4 & $\mathrm{~N}$ & 2.2 \\
\hline
\end{tabular}

$(\mathrm{A})=$ without the addition of glycerol and sucrose into the dispersant; $(\mathrm{B})=$ with the addition of glycerol and sucrose into the dispersant; $\mathrm{N}=$ not detected.

of those unknown compounds adsorbed on the surface of carbon nanotubes as well as additional cleanout procedures, however, somewhat decreased the detection limit for analysis of drugs in urine sample by mass spectrometry. For example, the detection limit of quinine extracted from $100 \mu \mathrm{L}$ urine samples and water is about $500 \mathrm{ppb}$ and $50 \mathrm{ppb}$ with $\mathrm{S} / \mathrm{N} \approx 3$, respectively.

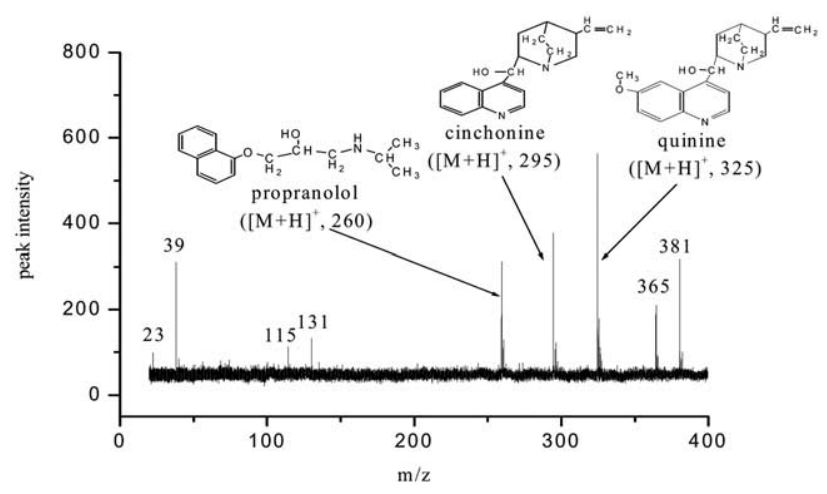

Figure 3. Mass spectra of analytes adsorbed on the surface of carbon nanotubes extracted from $100 \mu \mathrm{L}$ 3DrugMix solution containing propranolol $\left(260,[\mathrm{M}+\mathrm{H}]^{+}\right)$, cinchonine $(295,[\mathrm{M}+$ $\mathrm{H}]^{+}$), and quinine $\left(325,[\mathrm{M}+\mathrm{H}]^{+}\right.$) with concentration of each compound at $10 \mathrm{ppm}$. The dominant background peaks in the mass spectrum are $\mathrm{Na}^{+}, \mathrm{K}^{+}$, and the $\mathrm{Na}^{+} / \mathrm{K}^{+}$adduct ions with glycerol (at $m / z 115$ and 131) and sucrose (at $m / z 365$ and 381).

\section{Conclusion}

In summary, we developed a sample preparation technique for MALDI-MS to analyze small molecules with carbon nanotubes as adsorbent for solid-phase extraction and matrix simultaneously. It is found that with the addition of glycerol and sucrose into the dispersant, the intensity, $\mathrm{S} / \mathrm{N}$, and resolution of

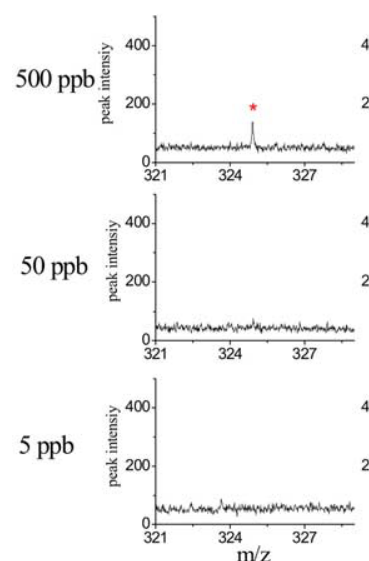

(a)
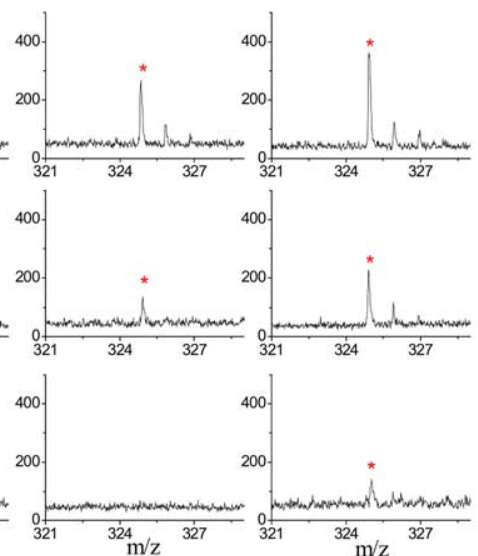

(b)

(c)

Figure 4. Mass spectra for quinine (marked with an asterisk) extracted by carbon nanotubes from its solution at different concentration. (a) Thin-layer method, (b) SPE method extracted from $100 \mu \mathrm{L}$ solutions, and (c) extracted from $1000 \mu \mathrm{L}$ solution. Concentration of quinine is at $500 \mathrm{ppb}, 50 \mathrm{ppb}$ and $5 \mathrm{ppb}$, respectively, from top to bottom. 


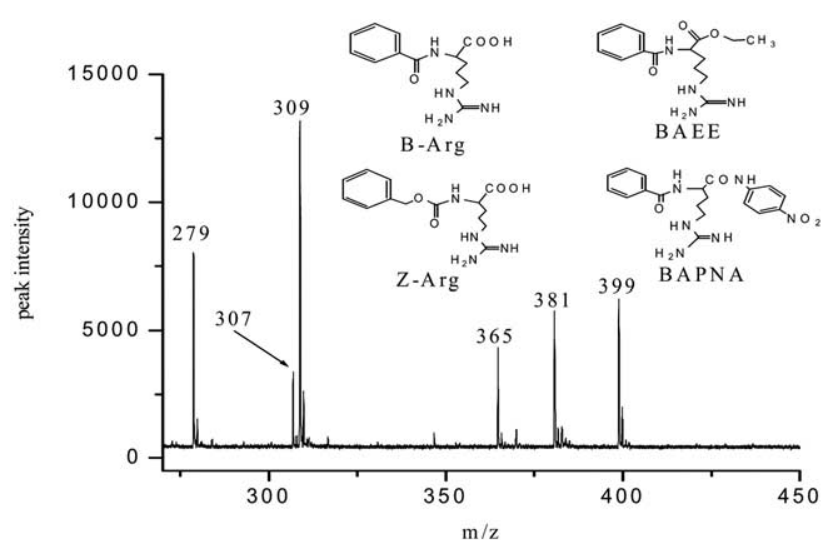

Figure 5. Mass spectrum of analytes adsorbed on the surface of carbon nanotubes extracted from $100 \mu \mathrm{L}$ solution of 3ArgMix with the concentration of $27.8 \mathrm{ppm}$ for B-Arg, $30.6 \mathrm{ppm}$ for BAEE and 39.8 ppm for BAPNA, followed by depositing $0.5 \mu \mathrm{L}$ solution of Z-Arg at $154 \mathrm{ppm}$. Peaks at $\mathrm{m} / \mathrm{z} 279,307,399$ and 309 are assigned to the $\mathrm{H}^{+}$ adduct ions of B-Arg, BAEE, BAPNA and Z-Arg, respectively. Spectrum is accumulated from 30 laser shots at 10 different laser spots, i.e., 300 laser shots total.

peaks for analytes by mass spectrometry increased significantly. In comparison with our previously reported method for depositing sample solution directly onto the thin-layer of carbon nanotubes, it is observed that the limit of detection for analytes can be enhanced about 10 to 100 times, attributable to solid-phase extraction of analytes in solution by carbon nanotubes. It also shows a great potential in quantitative analysis of low-mass compounds with properly introduced internal standard. As it is still in a preliminary stage for carbon nanotubes as matrix for MALDI-TOF-MS, the detection limit for analytes is somewhat unsatisfactory. However, the introduction of solid-phase extraction greatly simplified the sample preparation with integration of concentration, desalting and removing contaminants prior to MALDI-TOF-MS, and the practical application of carbon nanotubes as a kind of new matrix in MALDI-

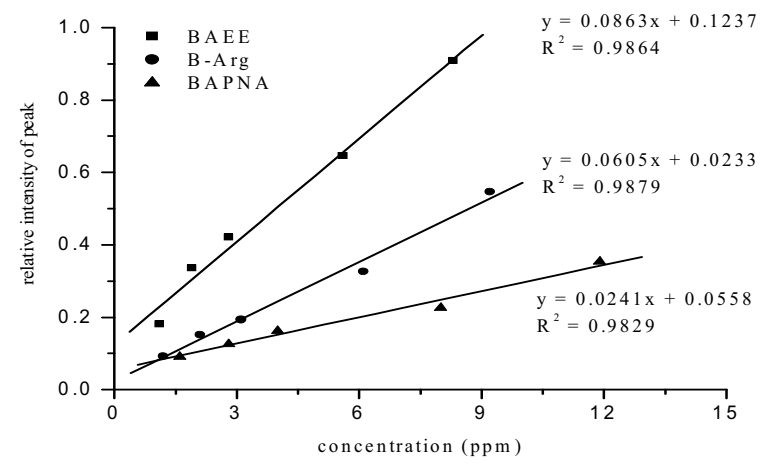

Figure 6. Quantitative calibration curves between the relative intensity $\left(\mathrm{I}_{\text {analytes }} / \mathrm{I}_{\mathrm{Z} \text {-Arg }}\right.$ ) of peaks for analytes to intensity of peak for Z-Arg and concentrations of analytes. Each dot is the average of five spectra and each spectrum is accumulated from 30 laser shots at 10 different laser spots, i.e., 300 laser shots in total for each.

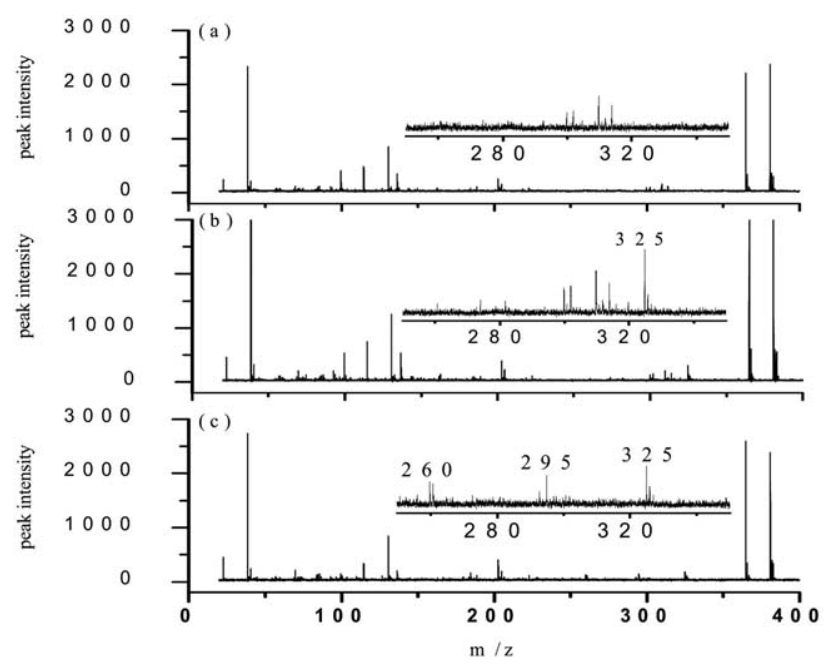

Figure 7. Mass spectra for drugs extracted from the urine sample by carbon nanotubes. (a) $100 \mu \mathrm{L}$ blank urine; (b) $100 \mu \mathrm{L}$ urine spiked with quinine $\left(325,[\mathrm{M}+\mathrm{H}]^{+}\right)$at concentration of $5 \mathrm{ppm}$; (c) $100 \mu \mathrm{L}$ urine spiked with 3DrugMix solution containing propranolol $\left(260,[\mathrm{M}+\mathrm{H}]^{+}\right)$, cinchonine $\left(295,[\mathrm{M}+\mathrm{H}]^{+}\right)$, and quinine $\left(325,[\mathrm{M}+\mathrm{H}]^{+}\right)$with concentration of each component at $3 \mathrm{ppm}$.

TOF-MS for direct analysis of low-mass compounds such as drugs in biological fluids has been realized.

\section{Acknowledgments}

Financial supports from the National Natural Sciences Foundation of China (20275038 and 20327002), the China State Key Basic Research Program Grant (001CB510202) and State High-Tech Program Grant (2003AA233061) and the Knowledge Innovation program of DICP to H.Z. are gratefully acknowledged.

\section{References}

1. Karas, M.; Hillenkamp, F. Laser Desorption Ionization of Proteins with Molecular Masses Exceeding 10,000 Daltons. Anal. Chem. 1988, 60, 2299-2301.

2. Tanaka, M.; Waki, H.; Ido, Y.; Akita, S.; Yoshida, T. Protein and Polymer Analyses up to $m / z$ 10,000 by Laser Ionization Time-of-Flight Mass Spectrometry. Rapid Commun. Mass Spectrom. 1988, 2, 151-153.

3. Harvey, D. J. Matrix-assisted Laser Desorption/Ionization Mass Spectrometry of Carbohydrates. Mass Spectrom. Rev. $1999,18,349-450$.

4. Fenselau, C.; Demirev, P. A. Characterization of Intact Microorganisms by MALDI Mass Spectrometry. Mass Spectrom. Rev. 2001, 20, 157-171.

5. Lay, J. O. MALDI-TOF Mass Spectrometry of Bacteria. Mass Spectrom. Rev. 2001, 20, 172-194.

6. Tang, K.; Opalsky, D.; Abel, K.; van den Boom, D.; Yip, P.; Del Mistro, G.; Braun, A.; Cantor, C. R. Single Nucleotide Polymorphism Analyses by MALDI-TOF MS. Int. J. Mass Spectrom. 2003, 226, 37-54.

7. Nielen, M. W. F. MALDI Time-of-Flight Mass Spectrometry of Synthetic Polymers. Mass Spectrom. Rev. 1999, 18, 309-344.

8. Cohen, L. H.; Gusev, A. I. Small Molecule Analysis by MALDI Mass Spectrometry. Anal. Bioanal. Chem. 2002, 373, 571-586.

9. Zhang, H.Y.; Andren, P. E.; Caprioli, R. M. Micro-Preparation Procedure for High-Sensitivity Matrix-Assisted Laser Desorption Ionization Mass Spectrometry. J. Mass Spectrom. 1995, 30, $1768-1771$. 
10. Gobom, J.; Nordhoff, E.; Mirgorodskaya, E.; Ekman, R.; Roepstorff, P. Sample Purification and Preparation Technique Based on Nano-Scale Reversed-Phase Columns for the Sensitive Analysis of Complex Peptide Mixtures by Matrix-Assisted Laser Desorption/Ionization Mass Spectrometry. J. Mass Spectrom. 1999, 34, 105-116.

11. Xiang, F.; Beavis, R. C. A Method to Increase Contaminant Tolerance in Protein Matrix-Assisted Laser-Desorption Ionization by the Fabrication of Thin Protein-Doped Polycrystalline Films. Rapid Commun. Mass Spectrom. 1994, 8, 199-204.

12. Brockman, A. H.; Dodd, B. S.; Orlando, R. A Desalting Approach for MALDI-MS Using on-Probe Hydrophobic Self Assembled Monolayers. Anal. Chem. 1997, 69, 4716-4720.

13. Brockman, A. H.; Shah, N. N.; Orlando, R. Optimization of A Hydrophobic Solid-Phase Extraction Interface for Matrix-Assisted Laser Desorption/Ionization. J. Mass Spectrom. 1998, 33, 1141-1147.

14. Schuerenbeg, M.; Luebbert, C; Eickhoff, H.; Kalkum, M.; Lehrach, H.; Nordhoff, E. Prestructured MALDI-MS Sample Supports. Anal. Chem. 2000, 72, 3436-3442.

15. Kjellstrom, S.; Jensen, O. N. In Situ Liquid-Liquid Extraction as a Sample Preparation Method for Matrix-Assisted Laser Desorption/Ionization MS Analysis of Polypeptide Mixtures. Anal. Chem. 2003, 75, 2362-2369.

16. Dekker, C. Carbon Nanotubes as Molecular Quantum Wires. Phys. Today 1999, 52, 22-28.

17. Dai, H. Controlling Nanotube Growth. Phys. World 2000, 13, 43-47.

18. Ren, Z. F.; Huang, Z. P.; Xu, J. W.; Wang, J. H.; Bush, P.; Siegal, M. P.; Provencio, P. N. Synthesis of Large Arrays of WellAligned Carbon Nanotubes on Glass. Science 1998, 282, 11051107.

19. Chen, J.; Hamon, M. A.; Hu, H.; Chen, Y.; Rao, A. M.; Eklund, P. C.; Haddon, R. C. Solution Properties of Single-Walled Carbon Nanotubes. Science 1998, 282, 95-98.

20. Wong, S. S.; Joselevich, E.; Woolley, A. T.; Cheung, C. L.; Lieber, C. M. Covalently Functionalized Nanotubes as Nanometre-Sized Probes in Chemistry and Biology. Nature 1998, 394, 52-55.

21. Iijima, S. Helical Microtubules of Graphitic Carbon. Nature 1991, 354, 56-58.

22. Iijima, S.; Ichihashi, T. Single-Shell Carbon Nanotubes of 1-nm Diameter. Nature 1993, 363, 603-605.

23. Long, R. Q.; Yang, R. T. Carbon Nanotubes as Superior Sorbent for Dioxin Removal. J. Am. Chem. Soc. 2001, 123, 2058-2059.

24. Davis, J. J.; Green, M. L. H.; Hill, H. A. O.; Leung, Y. C.; Sadler, P. J.; Sloan, J.; Xavier, A. V.; Tsang, S. C. The Immobilisation of
Proteins in Carbon Nanotubes. Inorg. Chim. Acta 1998, 272, 261-266.

25. Li, Y. H.; Wang, S. G.; Wei, J. Q.; Zhang, X. F.; Xu, C. L.; Luan, Z. K.; Wu, D. H.; Wei, B. Q. Lead Adsorption on Carbon Nanotubes. Chem. Phys. Lett. 2002, 357, 263-266.

26. Li, Y. H.; Wang, S. G.; Cao, A. Y.; Zhao, D.; Zhang, X. F.; Xu, C. L.; Luan, Z. K.; Ruan; D. B.; Liang, J.; Wu, D. H.; Wei, B. Q. Adsorption of Fluoride from Water by Amorphous Alumina Supported on Carbon Nanotubes. Chem. Phys. Lett. 2001, 350, 412-416.

27. Peng, X. J.; Li, Y. H.; Luan, Z. K.; Di, Z. C.; Wang, H. Y.; Tian, B. H.; Jia, Z. P. Adsorption of 1,2-Dichlorobenzene from Water to Carbon Nanotubes. Chem. Phys. Lett. 2003, 376, 154-158.

28. Cai, Y. Q.; Jiang, G. B.; Liu, J. F.; Zhou, Q. X. Multiwalled Carbon Nanotubes as a Solid-Phase Extraction Adsorbent for the Determination of Bisphenol A, 4-n-Nonylphenol, and 4-tert-Octylphenol. Anal. Chem. 2003, 75, 2517-2521.

29. Xu, S. Y.; Li, Y. F.; Zou, H. F.; Qiu, J. S.; Guo, Z.; Guo, B. C. Carbon Nanotubes as Assisted Matrix for Laser Desorption/ Ionization Time-of-Flight Mass Spectrometry. Anal. Chem. 2003, 75, 6191-6195.

30. Sunner, J.; Dratz, E.; Chen, Y. C. Graphite Surface Assisted Laser Desorption/Ionization Time-of-Flight Mass-Spectrometry of Peptides and Proteins from Liquid Solutions. Anal. Chem. 1995, 67, 4335-4342.

31. Dale, M. J.; Knochenmuss, R.; Zenobi, R. Graphite/Liquid Mixed Matrices for Laser Desorption/Ionization Mass Spectrometry. Anal. Chem. 1996, 68, 3321-3329.

32. Chen, Y. C.; Shiea, J.; Sunner, J. Thin-Layer Chromatography Mass Spectrometry Using Activated Carbon, Surface-Assisted Laser Desorption/Ionization. J. Chromatogr. A 1998, 826, $77-86$.

33. Han, M.; Sunner, J. An Activated Carbon Substrate Surface for Laser Desorption Mass Spectrometry. J. Am. Soc. Mass Spectrom. 2000, 11, 644-649.

34. Chen, Y. C.; Shiea, J.; Sunner, J. Rapid Determination of Trace Nitrophenolic Organics in Water by Combining Solid-Phase Extraction with Surface-Assisted Laser Desorption/Ionization Time-of-Flight Mass Spectrometry. Rapid Commun. Mass Spectrom. 2000, 14, 86-90.

35. Köster, C.; Castoro, J. A.; Wilkins, C. L. High Resolution Matrix-Assisted Laser Desorption Ionization of Biomolecules by Fourier Transform Mass Spectrometry. J. Am. Chem. Soc. 1992, 114, 7572-7574.

36. Castoro, J. A.; Wilkins, C. L. Ultrahigh-Resolution MatrixAssisted Laser-Desorption Ionization of Small Proteins by Fourier-Transform Mass-Spectrometry. Anal. Chem. 1993, 65, 2621-2627. 